\title{
SITUAÇÃO AMBIENTAL DA MICROBACIA HIDROGRÁFICA RIBEIRÃO IGUATEMI GUARAÇAI - SP
}

\author{
Marcelo Costa Buzutti ${ }^{1}$
}

\section{Sérgio Luis de Carvalho²}

\section{Gustavo de Oliveira Palla ${ }^{3}$}

RESUMO: Com o objetivo de analisar a situação ambiental da microbacia hidrográfica Ribeirão Iguatemi, que está localizada na cidade de Guaraçai SP limitada ao norte pelo rio Tietê e ao sul pelo rio Aguapeí, foram utilizadas técnicas de geoprocessamento para limitar o divisor de águas da microbacia. Também foram utilizados métodos de georreferenciamento para o refinamento do registro das imagens fusionadas e para verificação dos dados obtidos em campo além de vetorização da rede de drenagem e avaliação do nível de degradação das Áreas de Preservação Permanentes. Utilizou-se também o método de análise das características fisiográficas para analizar características de possivel inundação. Com os resultados das características fisiográficas presentes no Ribeirão Iguatemi, classificou-se segundo Oliveira (1997) a área de estudo como "parcialmente sujeita a enchentes", A densidade de drenagem determinada foi considerada como baixa segundo a classificação de Christofoletti (1969) e a microbacia foi classificada segundo Strahler (1957) como sendo de $5^{\underline{a}}$ ordem.

\footnotetext{
1, Acadêmico do Curso de Agronomia, Faculdade de Engenharia, Campus de llha Solteira. E-mail: buzutaum@gmail.com.

${ }^{2}$ Docente do Departamento de Biologia e Zootecnia da Faculdade de Engenharia de llha Solteira (UNESP). E-mail: sergicar@bio.feis.unesp.br.

${ }^{3}$ Engenheiro Agrônomo Gustavo de Oliveira Palla, UNESP- Ilha Solteira. E-mail: gustavopalla@yahoo.com.br.
} 


\section{INTRODUÇÃO}

As águas doces superficiais existentes, passíveis de serem utilizadas pelo homem deforma economicamente viável e sem grandes impactos ao meio ambiente, correspondem somente a $0,001 \%$ da água do Planeta. Apesar de tratar-se de um recurso extremamente escasso, os recursos hídricos disponíveis no globo são hoje suficientes para atender as necessidades de todos os seres humanos.

Contudo, o problema da escassez da água está relacionado, dentre outras questões, à desigual distribuição entre as diversas regiões, às exigências cada vez maiores de consumo, principalmente nos sistemas produtivos, à poluição e contaminação dos recursos naturais (SERHID, 1999).

Essa temática tem ocupado lugar de destaque nas conferências internacionais, onde se estima que " 80 por cento de todas as moléstias e mais de um terço dos óbitos dos países em desenvolvimento sejam causados pelo consumo de água contaminada e, em média, até um décimo do tempo produtivo de cada pessoa se perde devido a doenças relacionadas com a água" (CNUMAD, 1992). São necessárias ferramentas que possam auxiliar na classificação dos níveis de degradação dessas áreas e uma boa alternativa seria a ferramenta de Geoprocessamento que segundo CÂMARA \& MEDEIROS (1998), o é uma tecnologia que utiliza técnicas matemáticas e computacionais para tratar as informações geográficas. Essa tecnologia constitui-se em técnicas fundamentais para a manutenção de registros atualizados do uso da terra e dos corpos d'água.

\section{REVISÃO BIBLIOGRÁFICA}

\subsection{Bacia Hidrográfica}

A bacia hidrográfica é uma área de captação natural da água de precipitação que faz convergir o escoamento para um único ponto de saída. A bacia hidrográfica compõe-se de um conjunto de superfícies vertentes e de uma rede de drenagem formada por cursos de água que confluem até resultar em um leito único no seu exutório (Tucci, 1997). A bacia 
hidrográfica pode ser definida como área total de drenagem que alimenta uma determinada rede hidrográfica ou ainda como um espaço geográfico de sustentação dos fluxos d'água de um sistema fluvial hierarquizado (Brasil, 1987).

\subsection{Matas Ciliares}

As matas ciliares são formações vegetais que se encontram associadas aos corpos d'água, ao longo dos quais podem se estender por dezenas de metros a partir das margens e apresentar marcantes variações na composição florística e na estrutura comunitária, dependendo das interações que se estabelecem entre o ecossistema aquático e o ambiente terrestre adjacente. São sistemas particularmente frágeis face aos impactos promovidos pelo homem, pois, além de conviverem com a dinâmica erosiva e de sedimentação dos cursos d'água, alojam-se no fundo dos vales, onde naturalmente recebem os impactos da interferência humana sobre a bacia hidrográfica como um todo.

As matas ciliares funcionam como filtros, retendo defensivos agrícolas, poluentes e sedimentos que seriam transportados para os cursos d'água, afetando diretamente a quantidade e a qualidade da água e conseqüentemente a fauna aquática e a população humana. São importantes também como corredores ecológicos, ligando fragmentos florestais e, portanto, facilitando o deslocamento da fauna e o fluxo gênico entre as populações de espécies animais e vegetais.

Em regiões com topografia acidentada, exercem a proteção do solo contra os processos erosivos (MARTINS, 2001). Além disso, a ausência das sombras geradas pelas matas ciliares altera a temperatura da água, principalmente no verão. As margens sombreadas são locais habitados por microorganismos, peixes e outros organismos aquáticos. A redução ou o desaparecimento dessas espécies causa um desequilíbrio ecológico e a perda da diversidade da fauna aquática (PALONE, 2007).

\subsection{Geoprocessamento}


O Geoprocessamento é um conjunto de tecnologias de coleta de informações, de desenvolvimento e uso de sistemas que as utilizam, envolvendo atividades como sensoriamento remoto, modelagem numérica de terreno, processamento e imagens e outras atividades de captura de dados (RODRIGUES, 1990). As geotecnologias estão em um estágio que permite fazer uma análise espacial que combine o mapeamento dos problemas urbanos com informações físicas, demográficas, geográficas, topográficas ou de infra-estrutura. Auxiliando assim na adoção de soluções para diversos problemas de uma forma mais racional e rápida (CORDOVEZ, 2002).

\subsection{Sensoriamento Remoto}

Sensoriamento Remoto consiste na utilização conjunta de modernos instrumentos (sensores), equipamentos para processamento e transmissão de dados e plataformas (aéreas ou espaciais) para carregar tais instrumentos e equipamentos, com o objetivo de estudar o ambiente terrestre através do registro e da análise das interações entre a radiação eletromagnética e as substâncias componentes do planeta Terra, em suas mais diversas manifestações (NOVO,1989). Já para CURRAN (1985), o sensoriamento remoto ampliou a capacidade do homem em obter informações sobre os recursos naturais e o meio ambiente, colocando-se como mais uma ferramenta complementar para facilitar trabalhos temáticos e de levantamentos.

\section{MATERIAL E MÉTODOS}

\subsection{Caracterização da Área de Estudo}

O município de Guaraçaí localiza-se na região noroeste do Estado de São Paulo na província geomorfológica do Planalto Ocidental Paulista. Integrante da região administrativa de Araçatuba, com uma extensão territorial de 568 km². Guaraçaí limita-se ao norte com o rio Tietê e ao Sul com o rio Aguapeí, integrando duas importantes Unidades de Gerenciamento de Recursos Hídricos do oeste paulista: Bacia Hidrográfica do Baixo Tietê e Bacia Hidrográfica do rio Aguapeí. A microbacia hidrográfica Ribeirão 
Iguatemi, esta localizada na porção norte do município possuindo uma área de $43,7 \mathrm{~km}^{2}$ sendo ocupada por pastagens e pela cultura do abacaxi.

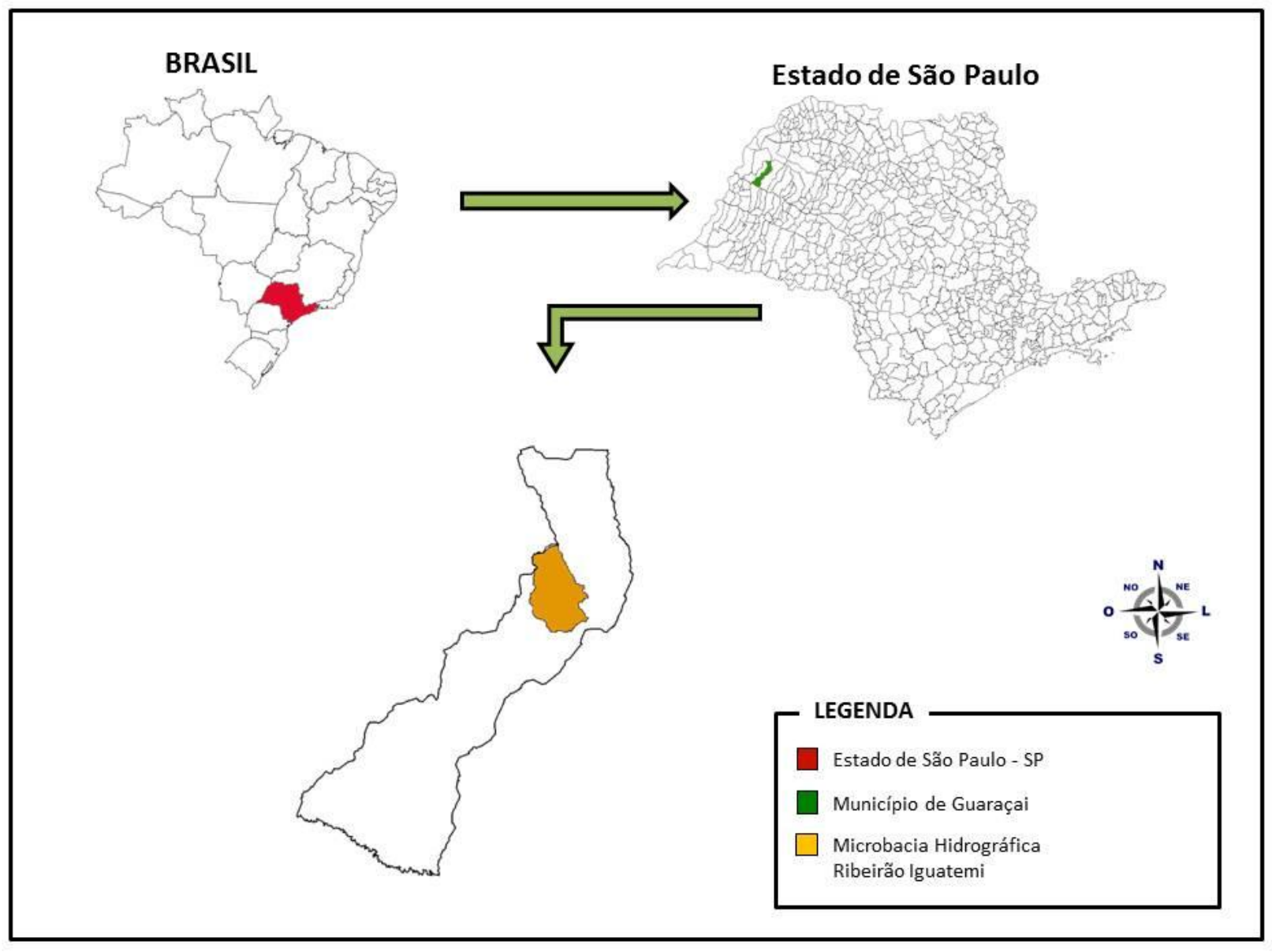

Figura 1. Localização da área de estudo microbacia

\subsection{Metodologia}

Foi obtida a imagem ortorretificada do LANDSAT 7, sensor ETM+, órbita/ponto 222/75 do dia 28 de abril de 2006 disponibilizada no site do Global Land Coveracility(http://glcf.umiacs.umd.edu/data/landsat/). Esta imagem foi utilizada para o georreferenciamento da imagem atualizada do satélite CBERS-2B, sensores CCD e HRC que cobre a microbacia hidrográfica. Foi utilizada a imagem orbital do satélite CBERS-2B, sensor CCD com resolução espacial de 20 metros e sensor HRC com resolução de 2,5 metros, obtidas através do site do Instituto Nacional de Pesquisas Espaciais - INPE (http://www.inpe.br) acessado no dia 13 de julho de 2010. AS imagens orbitais da câmera 
de média resolução, CCD, utilizada foi a orbitas/pontos 159/123 do dia 06/01/2010. Em relação às imagens de alta resolução do sensor HRC, também disponibilizadas no mesmo site do INPE, foram obtidas quatro imagens das seguintes orbitas/pontos: 159_A/123_1 do dia 27 de setembro de 2009, 159_A/123_2 do dia 27 de setembro de 2009, 159_B/123_1 do dia 05 de outubro de 2009, 159_A/123_5 do dia 27 de setembro de 2009. Para o desenvolvimento do trabalho foi utilizado o software de domínio público SPRING (Sistema de Informações Georreferenciadas) na versão 5.2.1, desenvolvido pelo INPE.

Inicialmente foi criado o Banco de Dados denominado Ribeirão Iguatemi, dentro deste Banco de Dados foi criado o projeto também denominado Ribeirão Iguatemi. Foi adotada a projeção Universal Transverse Mercator (UTM) e datum de referência SIRGAS2000. O passo seguinte foi a importação da imagem ortorretificada do satélite LANDSAT para o projeto Ribeirão Iguatemi Na etapa seguinte, foi realizada a operação de registro da imagem CCD/CBERS tomando como referência a imagem LANDSAT 7/ETM+ ortorretificada. Em seguida foi realizada a técnica de restauração da imagem CCD/CBERS. Posteriormente utilizando como referência a imagem CCD/CBERS foi efetuado o registro das imagens CBERS, sensor HRC.

Como cada imagem do sensor HRC cobre uma área 1/25 da imagem CCD, inicialmente foi realizado o processo denominado Reamostragem. Após essa etapa foi utilizada a técnicas de fusão Intensidade-Matiz-Saturação (IHS). Após essa etapa foi gerado o mosaico das imagens HRC fusionadas. Finalmente foi realizado um refinamento no georreferenciamento dessas imagens utilizando 30 pontos de controle coletados em campo através de um conjunto GPS Geodésico modelo SYSTEM 1200 - RTK da marca LEICA. Esta etapa teve como finalidade a conferência de pontos de apoio (georreferenciados) para fornecer controle às imagens orbitais usadas no projeto. A metodologia utilizada seguiu as normas técnicas oficiais vigentes NBR/ABNT 13.133/94, LEI 10267/INCRA. Na etapa seguinte foi realizada a vetorização da rede de drenagem e do divisor de água da microbacia.

Após a identificação dos canais de drenagem, foi utilizada a ferramenta Edição Vetorial para traçar as linhas que representam os seguintes dados da rede de drenagem: leito seco e canal perene. Em seguida foram identificadas e digitalizadas as nascentes. Nas regiões da microbacia onde os canais de drenagem eram muito estreitos e não 
possuíam áreas úmidas, a rede de drenagem foi digitalizada através do Método das Crênulas (BIASI, 1970) que utiliza as inflexões das curvas de nível presentes nas cartas do IGGSP registradas e com o auxílio das imagens de alta resolução espacial disponíveis no Google Earth.

$\mathrm{Na}$ etapa seguinte foi realizada a hierarquização de toda a rede de drenagem da bacia hidrográfica, utilizando o método proposto por Strahler (1964). A avaliação da acurácia do divisor de água foi realizada através de coleta de pontos obtidos em campo com GPS geodésico e a das nascentes foi verificada através de trabalhos de campo em 15 das nascentes distribuídas aleatoriamente correspondente a uma amostra representativa do total de 153 nascentes existentes na bacia hidrográfica. O processo de caracterização fisiográfica consiste na determinação de uma série de fatores como: área de drenagem, fator de forma, coeficiente de compacidade, sistema de drenagem, ordem dos canais, densidade de drenagem, extensão média do escoamento superficial. Moura (2008) afirma que o processo de caracterização fisiográfica em bacias é essencial para a elaboração e implementação de futuros projetos, pois, os resultados auxiliam na compreensão do escoamento superficial de uma bacia hidrográfica. $O$ fator área de drenagem segundo Andrade et al. (2008) compreende à medida em projeção horizontal, em que, é considerada toda a área da bacia hidrográfica.

Normalmente seus resultados são expressos em $\mathrm{km}^{2}$. Para a determinação do formato da bacia, é necessária a obtenção de dois outros fatores: Coeficiente de compacidade $(\mathrm{Kc})$ esse fator relaciona o perímetro de uma bacia e a circunferência de área igual presente na respectiva bacia, quanto mais irregular a forma da bacia hidrográfica, maior será esse índice (Carvalho et al., 2009). Seu cálculo utiliza a seguinte expressão:

$$
K c=0,28 \cdot \frac{p}{\sqrt{A}}
$$

Onde: $\mathrm{Kc}=$ coeficiente de compacidade (adimensional); $\mathrm{P}=$ perímetro $(\mathrm{km}) ; \mathrm{A}=$ área $\left(\mathrm{km}^{2}\right)$ ; O Fator Forma (Kf) é determinado através da razão entre a largura média da bacia e o comprimento axial da mesma. Andrade et al. (2008) complementam que esse fator é obtido com a medição do comprimento desde a desembocadura até a cabeceira da bacia. $\mathrm{O}$ cálculo desse fator é determinado pela equação:

$$
F=\frac{A}{L^{2}}
$$


Onde: $\mathrm{F}=$ Fator de Forma (adimensional); $\mathrm{A}=$ Área $\left(\mathrm{km}^{2}\right) ; \mathrm{L}=$ Comprimento do eixo principal $(\mathrm{km})$; Indice de circularidade (Ic) esse índice possui uma variação de acordo com o formato da bacia. Tende para unidade em bacias circulares e diminui em bacias com formatos alongados. Segundo Andrade et al. (2008), esse índice relaciona o perímetro da bacia e a sua área. A determinação desse fator utiliza a seguinte equação:

$$
\text { Ic }=\frac{12,57 \cdot A}{p^{2}}
$$

Onde: $\mathrm{Ic}=$ índice de circularidade (admensional); $\mathrm{A}=$ área de drenagem $\left(\mathrm{m}^{2}\right) ; \mathrm{P}=$ perímetro (m); O parâmetro sistema de drenagem é composto pelo rio principal de uma bacia hidrográfica e por seus tributários. A determinação referente ao sistema de drenagem possibilita a deliberação sobre o maior ou menor tempo que a água demora a deixar uma bacia hidrográfica. Alguns parâmetros são fundamentais no estudo do sistema de drenagem: Ordem dos Canais, Densidade de Drenagem e Extensão média do Escoamento Superficial; $O$ parâmetro ordem dos canais se refere a uma classificação sobre o grau de ramificações e/ou bifurcações presentes em uma bacia hidrográfica. A classificação de ordenamento dos cursos mais utilizada é a proposta por Horton (1945) e modificada por Strahler (1957); Segundo Carvalho et al. (2009), a densidade de drenagem indica a real eficiência da drenagem atuante na bacia hidrográfica. Sua determinação consiste numa relação entre o comprimento total dos cursos d'água e a área de drenagem. O parâmetro é obtido através da equação:

$$
D d=\frac{R d}{A}
$$

Onde: $\mathrm{Dd}=$ é a densidade de drenagem $\left(\mathrm{km} / \mathrm{km}^{2}\right) ; R d=$ rede de drenagem $(\mathrm{km}) ; A=$ é a área da bacia $\left(\mathrm{km}^{2}\right)$; Extensão média do escoamento superficial esse parâmetro relaciona a distância média que a água proveniente das precipitações, teria que escoar sobre a bacia em linha reta do ponto onde ocorreu a sua queda até o ponto mais próximo do leito de qualquer curso d'água. Para facilitar a obtenção do parâmetro, a bacia é modificada para forma de retângulo com uma mesma área, no qual, o lado maior é a soma dos comprimentos da bacia (Vilella \& Mattos, 1975). Sua obtenção é ocasionada através da equação:

$$
l=\frac{A}{4 L}
$$

Onde: $\mathrm{A}=$ área $(\mathrm{km} 2) ; \mathrm{L}=$ Comprimento do rio principal $(\mathrm{km})$. 


\section{RESULTADOS E DISCUSSÃO}

Com os resultados das características fisiográficas presentes no Ribeirão Iguatemi (Tabela 1), classificou-se segundo Oliveira (1997) a área de estudo como "parcialmente sujeita a enchentes", pois, o Kc obtido foi de 1,33. Utilizando ainda esse parâmetro foi possível concluir que a microbacia tende a forma circular, pois, o valor determinado está próximo da unidade. Segundo Villela \& Matos (1975) bacias hidrográficas que apresentam formatos alongados, são pouco predispostas a enchentes, pois, apresentam menores concentrações de deflúvio.

Tabela 1. Parâmetros fisiográficos determinados para a Microbacia do Córrego da Véstia

\begin{tabular}{ll}
\hline Parâmetro & Dimensões \\
\hline Área de drenagem & $43,7 \mathrm{~km}^{2}$ \\
\hline Perímetro & $31,49 \mathrm{~km}$ \\
\hline Comprimento do rio principal & $9,96 \mathrm{~km}$ \\
\hline Coeficiente de compacidade (Kc) & 1,33 \\
\hline Fator forma (Kf) & 0,43 \\
\hline İndice de circularidade (Ic) & 0,55 \\
\hline Ordem dos canais & $5^{\mathrm{a}}$ ordem \\
Densidade de drenagem & $1,64 \mathrm{~km} / \mathrm{km}^{2}$ \\
\hline
\end{tabular}

Com relação ao Kf, verificou-se também que a área de estudo está sujeita a processos de inundação, visto que, o valor adquirido foi de 0,43. De acordo Wisler \& Brater (1964), valores baixos para esse parâmetro, comprovam que, essas bacias hidrográficas são pouco propensas aos processos de inundações quando confrontadas com bacias de mesma dimensão, que apresentem um Kf mais elevado. 
O valor obtido para o parâmetro Ic foi de 0,55, demonstrando que a microbacia de estudo apresenta dificuldades com o escoamento superficial da chuva, devido ao seu formato que tende a ser circular. Muller (1953) e Schumm (1956) rotulam o Ic de três formas: valores < 0,51 demonstram que a bacia tende a ser mais alongada e tem como tendência o favorecimento do escoamento; = 0,51 demonstra um nível moderado de escoamento e valores > 0,51 apresentam forte indício de que a bacia tende a um formato circular, o que favorece os processos de enchentes.

A densidade de drenagem determinada foi de $1,64 \mathrm{~km} / \mathrm{km}^{2}$, sendo considerada como baixa segundo a classificação de Christofoletti (1969), pois, o valor determinado foi bem inferior a $<7,5 \mathrm{~km} / \mathrm{km}^{2}$. O baixo resultado obtido para esse parâmetro, de acordo com Christofoletti (1980), classifica essa microbacia como sendo pouco suscetível a processos erosivos naturais. Segundo Carvalho et al. (2009), a obtenção de baixos valores para a esse parâmetro, estão geralmente relacionados com regiões de rochas permeáveis e de regime pluviométrico com chuvas de baixa intensidade.

O Ribeirão Iguatemi foi classificado segundo a classificação de Strahler (1957) como sendo de $5^{\mathrm{a}}$ ordem. A ordem dos canais corresponde ao grau de ramificação ou bifurcação presente em uma bacia. Esse resultado indica que a área de estudo apresenta sistema de drenagem muito ramificado. Segundo Tonello et al. (2006), o número de ramificações abaixo de 4 é considerado trivial em pequenas bacias, e , quanto mais elevado o índice obtido para esse fator, maior será a rede de drenagem de uma bacia.

A figura 2 apresenta a situação ambiental da Microbacia Hidrográfica do Ribeirão Iguatemi com a Área de Preservação Permanente e os níveis de degradação. 
SITUAÇÃO AMBIENTAL DA MICROBACIA HIDROGRÁFICA RIBEIRÃO IGUATEMI, GUARAÇAÍ-SP
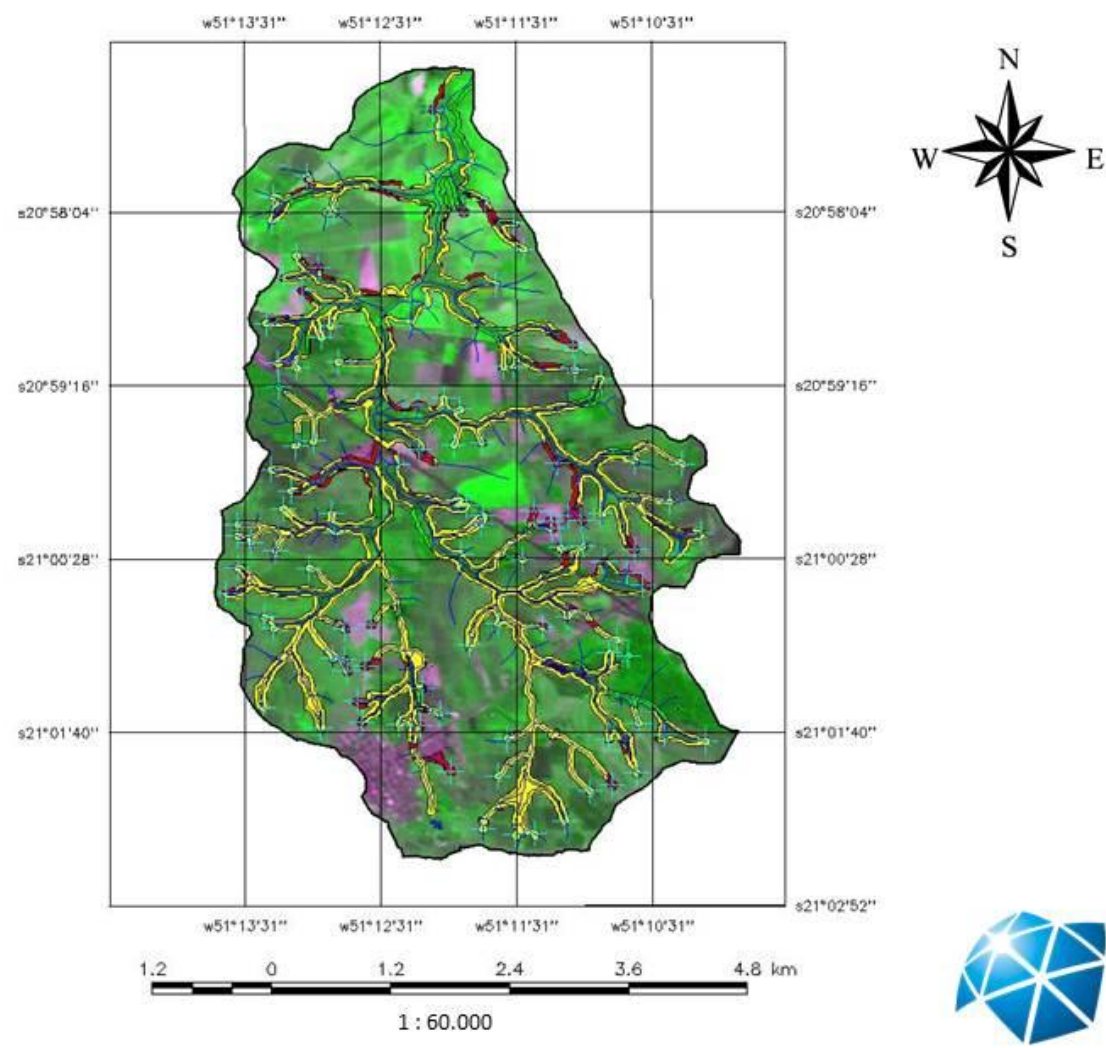

\begin{tabular}{|l|}
\hline \\
$\square$ Área degradada \\
$\square$ Parcialmente degradada \\
$\square$ vegetação conservada \\
- Rede de Drenagem \\
- Limite da Bacia Hidrográfica \\
+ Nascentes \\
\hline Satélite: CBERS \\
Órbita/Ponto: $159 / 123$ \\
Data: 06/01/2010 \\
Projeção: UTM \\
Datum: WGS84 \\
Execução: \\
Marcelo Costa Buzutti \\
Sérgio Luis de Carvalho \\
Gustavo de Oliveira Palla
\end{tabular}

Laboratório de Geoprocessamento

FE - UNESP

Ilha Solteira

Figura 2. Ilustração da área de preservação permanente (APP) e os níveis de degradação.

O estudo sobre as informações da Tabela 2, demonstra que a microbacia hidrográfica Ribeirão Iguatemi tem uma área de preservação permanente de 675,60 ha, nela estão presentes 568,04 ha que apresentam (virgula ao invés de pontos) níveis parciais de degradação e 67,96 ha se encontram em níveis de degradação total. Em números bem menos expressivos a área de vegetação preservada apresenta 39.60 há. 
Tabela 2. Níveis de degradação em área na Microbacia Córrego Ipê

\begin{tabular}{ll}
\hline Nível de Degradação & Área \\
\hline Vegetação conservada & 39.60 ha \\
\hline Vegetação parcialmente degradada & 568.04 ha \\
\hline Vegetação degradada & 67.96 ha \\
\hline
\end{tabular}

\section{5 . CONCLUSÕES}

Através dos dados analisados pode-se avaliar um alto nivel de degradação da bacia que chega a $84 \%$ da Area de Preservação Permanente (APP) em nivel parcial de degradação, $10 \%$ com nivel total de degradação e apenas $6 \%$ da APP preservada. Relacionando-se esses resultados com os dados da análise fisiográfica, que indica uma bacia com pouca tendencia a inundações, fica demonstrado que não é a sua morfologia a responsável pela degradação das APPs. Conclui-se que essa degradação está relacionada a má conservação do solo na região, a qual pode estar ligada a um manejo inadequado na agricultura.

\section{REFERÊNCIAS}

ANDRADE, N.L.R. de; XAVIER, F.V.; ALVES, E.C.R. de F. SILVEIRA, A.; OLIVEIRA, C.U.R. de. 2008. Caracterização morfométrica e pluviométrica da bacia do Rio Manso MT. Revista Brasileira de Geociências, 27, 2, 237-248.

BRASIL, MINISTÉRIO DA AGRICULTURA, 1987. Programa Nacional de Microbacias Hidrográficas : Manual Operativo. Brasília, DF. 60p.

BIASI, M. Carta de declividade de vertentes: confecção e utilização. Geomorfologia. São Paulo. 21-8-12, 1970.

CÂMARA, G.; MEDEIROS, J. S. Monitoramento da ocupação agrícola. In: Assad, E . D.; Sano, E. E. Sistemas de informação geográfica: Aplicações na agricultura. 2 ed. Brasília. Embrapa - CPAC, 1998, Cap. 1, p. 3-11. 
CARVALHO, W.M. de C.; Vieira, E. de O.; Rocha, J.M.J.; Pereira, A.K. dos S.; CARMO, T.V.B. 2009. Caracterização Fisiográfica da Bacia Hidrográfica do Córrego do Malheiro, no município de Sabará - MG. Revista Irriga, 14, 3, 398-412.

CHRISTOFOLETT, A. Análise morfométrica de bacias hidrográficas. Notícia Geomorfológica. v.18, n. 9, p. 35-64. 1969.

CONFERÊNCIA DAS NAÇÕES UNIDAS SOBRE MEIO AMBIENTE E DESENVOLVIMENTO (CNUMAD). Agenda 21, Rio de Janeiro, 1992.

CORDOVEZ, J. C. G. Geoprocessamento como ferramenta de gestão urbana. In: SIMPÓSIO REGIONAL DE GEOPROCESSAMENTO E SENSORIAMENTO REMOTO, 2002, Aracajú. Anais... Aracajú, s.n., 2002.

CHRISTOFOLETT, A. Geomorfologia. São Paulo: Editora Edgard Blücher / EDUSP, 1980. $150 \mathrm{p}$.

CHRISTOFOLETT, A. Análise morfométrica de bacias hidrográficas. Notícia Geomorfológica. v.18, n. 9, p. 35-64. 1969.

CURRAN, P. J. Principles of remote sensing. London: Longman, 1985, 282p.

HORTON, R.E. 1945. Erosional development of streams and their drainage basins: hidrophysical approach to quantitative morphology. Bulletim Geologic Society of America, v.56, n. 3, p. 275-370.

MARTINS, S. V. Recuperação de matas ciliares. Viçosa: Aprenda fácil, 2001. Fonte resumida.

MOURA, R.S. Caracterização Fisiográfica e Regionalização de Vazão na Microbacia do Córrego do Boi, Aparecida D'Oeste, SP. 2008. Monografia (Engenharia Agronômica). Faculdade de Engenharia do Campus de Ilha Solteira -UNESP. Ilha Solteira - SP, 48p.

MULLER, V.C. A quantitative geomorphology study of drainage basin characteristic in the Clinch Mountain Area. New York: Virginia and Tennesse. Dept. of Geology. n. 3, p. 30, 1953.

NOVO, E., 1989. Sensoriamento remoto, princípios e aplicações.:Edgard Blucher, São Paulo, 308 páginas. 
OLIVEIRA, J.N. 1997. Classificação de características fisiográficas. Texto básico para a disciplina "Hidrologia Básica". Ilha Solteira, SP: UNESP, 5p.

Palone, R. S.; Todd, A. H. Chesapeake BayRiparian Handbook: a guide for establishing and maintaining riparian forest buffers. USDA Forest Service, NA-TP-02-97. Radnor-PA, 1997.

RODRIGUES, M. Introdução ao geoprocessamento. Anais. Simpósio brasileiro de geoprocessamento. São Paulo: Universidade de São Paulo, 1990. p. 1-26.

SECRETARIA DE RECURSOS HÍDRICOS (SERHID) (RN). A água é um bem de todos. 1999.STRAHLER, A. N. 1957. Quantitative analysis of watershed geomorphology. Transaction of America Geophysics Union, v. 38. p 913-920. 1957.

SCHUMM, S. A. Evolution of drainage systems and slopes in badlands of Perth Amboy. Geological Society of America Bulletin, n. 67, p. 597-646, 1956.

TONELLO, K. C.; DIAS, H. C. T.; SOUZA, A. L.; ALVARES, C. A.; RIBEIRO, S.;

LEITE, F. P. Morfometria da Bacia Hidrográfica da Cachoeira das Pombas, Guanhães MG. Revista Árvore, v.30, n.5, p.849-857, 2006.

TUCCI, C. E. M. Controle de enchentes. In. TUCCI,C. E. M. (Org.) Hidrologia: ciência e aplicação.2.ed. Porto Alegre: UFRGS/ABRH, 2000. p.651-658.

VILELLA, S. M.; MATOS, A. Hidrologia Aplicada. São Paulo: Editora McGraw-Hill, 1975. $245 p$.

WISLER, C. O.; BRATER, E. F. Hidrologia. Tradução e publicação de Missão NorteAmericana pela Cooperação Econômica e Técnica no Brasil. Rio de Janeiro: Ao Livro Técnico S.A. 1964. 484p. 